\title{
Personality characteristics of victims of intimate partner violence: A systematic review ${ }^{\text {is }}$
}

\author{
Miguel Esteves Pereira ${ }^{\mathrm{a}}$, Andreia Azeredo ${ }^{\mathrm{a}, *}$, Diana Moreira ${ }^{\mathrm{a}}$, Isabel Brandão ${ }^{\mathrm{a}}$, \\ Fernando Almeida ${ }^{\mathrm{a}, \mathrm{b}, \mathrm{c}, \mathrm{d}}$

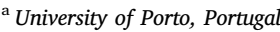 \\ ${ }^{\mathrm{b}}$ University Institute of Maia, Portugal \\ ${ }^{c}$ Porto Lusíadas Hospital, Portugal \\ ${ }^{\mathrm{d}}$ Instituto de Investigação e Inovação em Saúde (i3S), Portugal
}

\section{A R T I C L E I N F O}

\section{Keywords:}

Personality

Marriage

Family relations

Domestic violence

Intimate partner/marital abuse

Marriage and close relationships

\begin{abstract}
A B S T R A C T
Intimate partner violence (IPV) is global public health issue and refers to the violence committed by a partner in the context of an intimate relationship, regardless of whether or not it is legally recognized. This review aims to analyze the personality characteristics present in victims of IPV, addressing the causes and consequences of the abusive relationship. Studies focusing on female victims were obtained through multiple databases, following the Cochrane Collaboration procedures. Of the 87 documents collected, 31 were retained for further analysis and considered eligible for inclusion, with ten studies from manual search being included. The objectives, methodological aspects (sample/instruments), and main conclusions were extracted from each study. The results suggest that women tend to become victims when they experience violence during childhood, when they are economically dependent, lack social support, and fear for their lives. The consequences consist of physical and psychological sequelae that remain throughout life. There are personality traits that make the victim susceptible to remaining in an abusive relationship. Women who have experienced IPV obtained higher scores in schizoid, avoidant, self-destructive, schizotypal, borderline, and paranoid personality scales. Therefore, female victims exhibit characteristics such as low personal self-esteem, family and social isolation, dependency (economic and emotional), insecurity, inferiority, submissiveness, and pacification. This review is particularly useful for clinical practice and intervention with victims of IPV, by bringing to light specific personality traits, cognitive schemas and/or possible diagnoses that are most common among these victims and make them more vulnerable to remaining in abusive relationships.
\end{abstract}

\section{Introduction}

This review aims to understand (1) consequences of different types of violence for the victims of intimate partner violence (IPV), (2) the factors that contribute to remaining in the abusive relationship, and (3) the personality traits that are most common in IPV. This systematic review focuses on empirical and theoretical studies and was conducted in accordance with the guidelines of the Cochrane Collaboration (Higgins \& Green, 2011).
Violence against women is endemic worldwide and is present in all classes, races, ages, and religions. According to the United Nations Declaration, violence against women includes any act of gender-based violence that results in, or is likely to result in, physical, sexual, or psychological harm or suffering to women, including threats of such acts, coercion or arbitrary deprivations of liberty, whether occurring in public or private life (United Nations, 1993; World Health Organization [WHO], 2013). The most common type of violence against women worldwide is "domestic violence" or the physical, emotional, and/or

\footnotetext{
Miguel Esteves-Pereira, Faculty of Medicine, University of Porto (Portugal). Andreia Azeredo and Diana Moreira, Laboratory of Neuropsychophysiology, Faculty

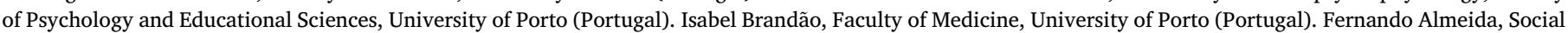

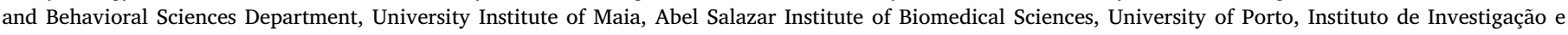
Inovação em Saúde (i3S), and Porto Lusíadas Hospital (Portugal).

The authors do not have financial, personal, or professional conflicts of interests. After the local ethics committee approved the study, it was conducted according to APA ethical standards. This research was not funded by any institution.

* Corresponding author at: Faculdade de Psicologia e de Ciências da Educação, Universidade do Porto, Rua Alfredo Allen, 4200-135, Porto, Portugal.

E-mail address: andreia_azeredo_13@hotmail.com (A. Azeredo).
} 
sexual abuse of women by their intimate partners or ex-partners (Heise, Ellsberg, \& Gottemoeller, 1999a, 1999b). Therefore, IPV refers to the violence committed by a partner in the context of an intimate relationship, regardless of whether or not it is legally recognized (Ravazzola, 1997). The perpetration of IPV by male partners is considered not only a severe human rights violation, but also a global public health issue. Indeed, in a multi-country study, estimates of lifetime prevalence of IPV ranged from $13 \%$ to $61 \%$, with most estimates varying between $23 \%$ and $49 \%$ (WHO, 2013). Similar numbers were found in a survey including almost 50 countries, in which $10 \%$ to $52 \%$ of women reported having experienced abuse by a partner at some point in their lives (Heise et al., 1999a, 1999b). Other studies have reported estimates between $4 \%$ and $49 \%$ for physical violence, $6 \%$ and $59 \%$ for sexual violence, and between $15 \%$ and $71 \%$ for physical or sexual violence, or both, by an intimate partner (Garcia-Moreno, Jansen, Ellsberg, Heise, \& Watts, 2006).

Narrowing in on the United States specifically, IPV rates have ranged between $20 \%$ to $60 \%$ (Heise, Pitanguy, \& Germain, 1994), with higher rates being observed in states where there is greater economic, political and legal disparity between men and women (Yllo \& Straus, 1990).

Similar rates were found further south, in Mexico, where $34 \%$ to $46 \%$ of adult women have reported experiencing violence by an intimate partner (Natera, Tiburcio, Berenzon, \& López, 1997; RamírezRodríguez \& Uribe-Vázquez, 1993; Saltijeral, Ramos, \& Caballero, 1999; Shiroma, 1996; Shrader Cox \& Valdéz Santiago, 1992). Nonetheless, research points toward the existence of differences in IPV rates between Latina and non-Latinas women, despite these similar estimates.

On the other hand, in Japan, there are lower rates of IPV compared to the United States, which researchers have attributed to Japan's more reserved and demure culture, as well as to advancements in gender equality (Kumagai, 1979; Kumagai \& Straus, 1983). Though not as expressive, IPV in Japan remains serious in nature and, nevertheless, presents some similarities with IPV in the United States. Specifically, the most frequent perpetrators of assault and battery against family members, in both Japan and the United States, are husbands and boyfriends (Craven, 1997; Keisatsucho, 1995). In addition, about one-third of female homicide victims in Japan are murdered by male intimate partners (Keisatsucho, 1995), which is a similar proportion to that observed in the United States (Federal Bureau of Investigation, 1995).

The prevalence rate of IPV in Cyprus is $21 \%$, similar to the $20 \%$ rate reported in Canada (Johnson \& Sacco, 1995), but significantly lower than values reported for marital rape in Bolivia (58\%), Puerto Rico (46\%) and Colombia (46\%) (Fischbach \& Herbert, 1997).

In Africa, higher rates of IPV are observed, with $20 \%$ to $71 \%$ of African women reporting abuse by their partners (Antai \& Antai, 2008; Jewkes, Levin, \& Penn-Kekana, 2002). A report by the domestic violence and victim support unit (DOVVSU) of Ghana indicated 15,495 cases of battered women, in 2011 (FIDA-Ghana - International Federation of Women Lawyers, 2013), and despite IPV quashing the hopes, standards and expectations these women held for intimate relationships, they tend to justify and remain in the violent relationship (Amoakohene, 2004; Ofei-Aboagye, 1994).

Specifically in Portugal, IPV is a social problem that emerged during the nineties (Mendes, Duarte, Araújo, \& Lopes, 2013) and varies according to cultural values, which hinders a universal conceptualization of violence, despite many shared aspects (Guimarães \& Pedroza, 2015).

In short, although IPV crosses not only national but also cultural boundaries, there are some differences in the rates and expression of IPV between countries and even within a specific country (Counts, Ayers, Brown, \& Campbell, 1992; Levinson, 1989). Nonetheless, it should be noted that most cross-cultural studies on the association between IPV and the status of women are mainly developed using a Western approach, from researchers to methodologies, and thus may fail to take into account sociocultural differences (Kumagai \& Straus,
1983).

In the year 2017, the profile of the female victim in a romantic relationship (86.6\%) included a mean age of 43 years, being married (38.2\%), having children (41.5\%), and being employed (42.7\%) (APAV, 2018). The violence committed may include physical, psychological, and/or sexual abuse, varying in frequency, severity, and intensity (Redondo, Pimentel, \& Correia, 2012). Psychological abuse, which includes threats, excessive jealousy and blackmail, is the most severe form of violence, since victims tend to minimize these behaviors and do to fully understand the severity of the violence (González-Ortega, Echeburúa, \& Corral, 2008; Hernando, 2007).

The question of whether women abandon or remain in a violent relationship has been a large focus of IPV research. Indeed, the most frequent queries in IPV literature, and by the public in general, are "Why do they stay?" and "Why don't they leave?" (Semaan, 2004). There is an abundance of assumptions and suppositions within the general population with regard to women who remain in abusive relationships, with many of them placing most blame on the victim, suggesting that these women invite the abuse due to certain personality shortcomings and masochistic traits (Blum, 1982; Shainess, 1979). However, these suppositions are no longer accepted, as research over the last decades has shown that women who experience physical, sexual, or psychological abuse by their partners do not derive enjoyment from their suffering, nor do they seek out punishment or abuse (Finkelhor, Gelles, Hotaling, \& Straus, 1983).

Besides IPV became increasingly recognized and discussed, important questions continuing to be insufficiently answered concerning the causes why women remain in an abusive relationship. Likewise, there is increasing recognition of the need for better data on the personality characteristics of victims of IPV.

\section{Method}

\subsection{Evidence acquisition and inclusion criteria}

Studies were identified through a search in multiple databases of EBSCOhost, including Criminal Justice Abstracts, Sociology Source Ultimate, Academic Search Complete, PsycINFO, and CINAHL Plus with Full Text. In order to avoid publication bias, these searches were supplemented with a manual search. Ancestral and forward searches were also conducted by examining bibliographies and locating studies citing each of the identified articles. To define the search expressions, an analysis of the keywords used in the articles on domestic violence was conducted, in order to collect the largest number of terms.

\subsubsection{Inclusion criteria}

Studies that addressed at least one of the following objectives were included: (1) consequences of different types of violence for the victims of IPV; (2) the factors that contribute to remaining in the abusive relationship; (3) the personality traits that are most common in victims of IPV.

\subsubsection{Exclusion criteria}

The reviewers considered, as exclusion criteria, case studies and articles focusing on the aggressors. Outside these criteria, no specific exclusion criteria were applied. Thus, only empirical studies and theoretical studies were considered herein.

The search results were analyzed independently by three researchers (MEP, AA, and DM), discrepancies were solved by the aid of one senior researcher (the last author), in order to reduce the probability of missing any study or as a way to minimize errors in the classification process (Higgins \& Green, 2011). The agreement index was assessed using Cohen's kappa and revealed a nearly perfect agreement; $K=0.980, p<.001$ (Landis \& Koch, 1997). Disagreements between reviewers were discussed and resolved by consensus. 


\subsection{Search strategy and data abstraction}

The keywords for the search were:

[AB (Domestic Violence OR Battered Woman OR Marital Violence) AND AB (Personality Traits OR Personal* OR Profile) AND AB (Woman and Victim)]

The search was not limited by any geographical, temporal, or linguistic factors.

A total of 87 studies, published between 1985 and 2019, were identified from all databases and search methods. Thirty duplicate studies were excluded. The abstracts of the remaining 57 studies were assessed, 21 of which were included: four from Criminal Justice Abstracts, five from Sociology Source Ultimate, three from Academic Search Complete, seven from PsycINFO, and two from CINAHL Plus with Full Text. Five studies were excluded because: $n=1$ were not related to the theme, $n=1$ were theoretical, $n=1$ were about the perception of IPV, $n=1$ were about the perspective about IPV, and $n=1$ were about the effects of alcohol in IPV. In addition, ten studies were included from manual search. In total, this systematic review comprised 31 articles. The objectives, methodological aspects (sample/ instruments), and main conclusions were extracted from each study. Three studies comprises the consequences of different types of violence for the victims of IPV (Objective 1), nine studies comprises the factors that contribute to remaining in the abusive relationship (Objective 2), four studies comprises the personality traits that are most common in victims of IPV (Objective 3), four studies relate objectives 1 and 2, two studies relate objectives 1 and 3, four studies relate the objectives 2 and 3 , and five studies comprises all three inclusion criteria or objectives (Fig. 1).

\section{Results}

\subsection{Consequences of different types of violence for the victims of IPV}

In a study with 553 women, only $18 \%$ had never experienced any type of abuse, $39 \%$ suffered and perpetrated verbal violence, $25 \%$ suffered physical violence, and $18 \%$ experienced severe violence with the use of some type of instrument (Verma \& Columbien, 2003). At times, the abuse was extreme, with $25 \%$ of women reporting that they received medical care due to the injuries (Fuentes et al., 2008).

Furthermore, during the dating period, $36 \%$ of women had already experienced abuse at the hands of their partners (Fuentes et al., 2008), which could be extended to the pregnancy phase (Fuentes et al., 2008;Pérez-Testor et al., 2007; Sarasua et al., 2007) and toward their children (Pérez-Testor et al., 2007; Sarasua et al., 2007). Psychological violence (insults, threats, belittlement, and humiliation) is the most common form (52\%), followed by physical violence (18\%) and, lastly, physical and psychological violence simultaneously (18\%) (Fuentes et al., 2008). Psychological abuse is, thus, associated with schemas concerning the rejection of connection, which includes the beliefs that others are not receptive to providing emotional support and/or that they will hurt the victim (Calvete et al., 2007).

The various types of abuse may lead to health problems for the victims, with the most common being psychological problems at $32 \%$, followed by physical problems at 19\% (Fuentes et al., 2008). Among the most reported psychological problems are posttraumatic stress disorder (PTSD) (Johnson \& Zlotnick, 2012; Sarasua et al., 2007), anxiety, depression, low self-esteem, and psychosocial maladjustment (Sarasua et al., 2007).

PTSD symptoms following domestic violence are related to a selfcritical personality style, namely control, competence, separation, autonomy, blame (Sharhabani-Arzy et al., 2005). Furthermore, the interaction between self-criticism and dependency contributes to an increase of the intensity of the PTSD symptoms, in the sense that women who exhibit low dependency tend to seek less social support, which increases the intensity of the PTSD symptoms (Sharhabani-Arzy et al.,
2005).

It is also common for victims of IPV to blame themselves for the violence they suffer. In fact, $40 \%$ of women report self-blame, most of which is attributed to their behavior (Andrews \& Brewin, 1990). When blame is assigned to the partners, $67 \%$ of victims attribute greater relevance to character than to the response to the context/situation (Andrews \& Brewin, 1990). Additionally, the attribution of self-blame evidenced in victims of IPV has a strong association with a depressive state and it is greater when the victims still maintain a relationship with the aggressor, whereas this attribution decreases when the victims are separated from their partners (Andrews \& Brewin, 1990). The manifestation of depressive symptoms is frequent, due to the failed attempt to abandon the disharmony of the relationship (Lima \& Werlang, 2011).

Latina women, in comparison to non-Latina women, exhibit more unfavorable results when it comes to depressive symptoms, social and personal self-esteem and symptoms related to the trauma (Edelson et al., 2007). Cultural differences are also visible regarding social support, with $37 \%$ of immigrants and Mexicans reporting having some type of support, compared to $70 \%$ of Spanish women (Alonso \& Labrador, 2008). Indeed, IPV may lead to suicide attempts by the victims (Lima \& Werlang, 2011; Sarasua et al., 2007).

In terms of psychosocial maladjustment, women report feeling more affected regarding their love lives, due to the inability to establish new relationships for fear of being victimized again (Fuentes et al., 2008). Psychological violence includes isolation from family and friends, as well as humiliation by their partners, which ranges from debasing the women individually to degrading the role of women and their place in society, through name-calling, insults, and sexual objectification (Yoshihama, 2002). This leads victims to develop beliefs about emotional deprivation and abuse, which, in turn, affect their choice to confront their partners and leave the relationship (Calvete et al., 2007). Thus, victims live in an unsafe environment in which their husbands control all their activities, limit their access to money, forbid them from going out (Fuentes et al., 2008; Hsieh, Feng, \& Shu, 2009; Pandey et al., 2009), and developing friendships (Hsieh et al., 2009; Pandey et al., 2009).

With regard to the age of the victims, younger victims typically experienced physical violence at a higher rate than older victims. Nonetheless, they also reported the violence and refrained from living with the aggressor at a higher proportion than older victims (Sarasua et al., 2007). It should also be noted that, although they exhibit a shorter victimization history given their young age, the phenomenon of IPV among these younger victims is still persistent, with $73 \%$ of them having already experienced violence during a period of 1 to 4 years (Sarasua et al., 2007).

\subsection{Factors that contribute to victims of IPV remaining in the abusive relationship}

Violence against women is tolerated due to socially imposed gender roles, which assign them a lower status (Ventura et al., 2013), and due to the transmission of experiences of violence throughout generations, in which victims often have witnessed violence during childhood (McLaughlin et al., 2010).

There are factors that make women more susceptible to maintain in an abusive relationship, such as witnessing or experiencing abuse during childhood (Alonso \& Labrador, 2008; Bensley et al., 2003; Lima \& Werlang, 2011; Pérez-Testor et al., 2007; Pico-Alfonso et al., 2008; Sarasua et al., 2007; Verma \& Collumbien, 2003; Walker \& Browne, 1985), and rigid adherence to traditional stereotypes of their roles as women (Walker \& Browne, 1985). Therefore, the acceptance of violence as something common is passed on from generation to generation, with childhood being crucial for the development of this pattern (Walker \& Browne, 1985), as well as the existing view that women are responsible for the balancing and maintaining the socially idealized family (Guedes et al., 2007). 




Fig. 1. Flowchart of literature search.

The victims of IPV remain in abusive relationships due to their desire to keep their family together for fear of losing their children (Guedes et al., 2007; Kelmendi, 2015), as well as insecurity, lack of family and social support (Alonso \& Labrador, 2008; Bui, 2003; Guedes et al., 2007), and fear of being killed (Hsieh et al., 2009; Pérez-Testor et al., 2007). In addition to these motives is the constant intimidation and belittlement that the partners carry out, by diminishing the victim as a person, making her feel inferior (Yoshihama, 2002).

It should also be noted that women's economic and emotional dependency on their partners not only increases the risk of violence and reluctance to report it (Kelmendi, 2015), but may also reduce the likelihood that victims leave or terminate the violent relationship (Bornstein, 2006). In cases where women do report abuse, this typically leads to an increase in the violence, as it is perceived as disrespectful toward the family (Kelmendi, 2015).

Of the victimized women, $63 \%$ took some sort of action against the violence, mainly separation from their partner (Ruiz-Perez et al., 2006). In general, these women are young, single, with a medium or high level of education, and financially independent (Ruiz-Perez et al., 2006). Not being married with the aggressor facilitates the separation process, since divorce normally entails a long legal process, which leads to more aggression that is usually more severe (Ruiz-Perez et al., 2006).

Since the escape is something they fear, victims develop behaviors in order to learn to withstand pain or to avoid situations that predispose the aggressor to violence (Walker \& Browne, 1985). These victim's behaviors occur due to 1) acceptance of the aggressor, 2) denial of the severity of the abuse, 3) pathological jealousy of aggressor, 4) the frequency and type of abusive behavior, 5) psychological abuse, and 6) death threats (Walker \& Browne, 1985).

Risk of violence increases when the age difference is equal to or less than five years between spouses, when there is an irregular distribution of financial contribution, when there is alcohol use, as well as a long duration of the marriage (Pandey et al., 2009). Moreover, risk of violence is also more frequent between the ages of 31 and 40 years (Fuentes et al., 2008). The education of women influences the likelihood of experiencing abuse, with $85 \%$ of victimized women having no education (Verma \& Collumbien, 2003). On the other hand, women who have a level of education equal or superior to that of their partner, or a stable job, easily seek help from multiple sources (family, friends, authorities, and health professionals) (Kaukinen et al., 2013). Therefore, risk perceptions were associated with decisions to maintain the relationship, in which women who perceived greater risk in remaining in the abusive relationship exhibited greater intention to terminate it (Harding \& Helweg-Larsen, 2009).

Low frequency or situational context possibly allowing the victim to "excuse" the aggressor (Pérez-Testor et al., 2007; Yoshihama, 2002). One in every three women expects their relationship to improve after the aggression, which leads to the minimization of conflicts, as well as the presence of ambivalent feelings that keep the victims from perceiving the danger as high, and lead them to maintain hope for 
improvement (Pérez-Testor et al., 2007).

Extended family is an extension of the individual self of female victims and, although family does not rigidly impose its identity and values on its members, it is regarded as fundamental in certain societies (Adjei, 2015). As an example, in the country of Ghana, parents are responsible for ensuring that their daughters are successful in marriage, in order to preserve family honor. In turn, it is the daughters' duty to preserve the social identity of the family. Therefore, this pressure to safeguard the family social identity may cause women to feel obliged to remain in violent relationships, since divorce would produce a bad reputation, interpreted as a bad woman, thus jeopardizing future marriages in that family (Adjei, 2015). Similarly, for Latina women, there is also intense pressure to remain in violent marriages or relationships, in order to preserve family unity and identity, a phenomenon that is referred to as familismo or marianismo (Edelson et al., 2007).

Women are taught to seek the approval of others, to be submissive, and to control aggressive behavior in order to maintain peace (Bui, 2003; Guedes et al., 2007; Walker \& Browne, 1985), thus impeding their acquisition of confrontation skills necessary to stop the abuse (Walker \& Browne, 1985). At the sociocultural level, defined gender roles contribute to inequality, because of the expectations they create for men and women, and there are some societies that, due to their patriarchal characteristics, tend to subordinate the status of women (Guedes et al., 2007; Kelmendi, 2015). Women are expected to fulfill their marital duties of caring for their children, spouses and homes, while sacrificing their own lives and identities for the sake of their family and marriage (Kelmendi, 2015). Therefore, although the family may be a system that provides financial and emotional support, it can also support the persistence of violence, by enforcing rigid gender roles through socialization, thus increasing gender inequality (Kelmendi, 2015).

Most women seek help from their personal network, close relatives or friends, in order to receive support to cope with or leave their abusive relationship (Bui, 2003). In cases where women have no social and/or family support, or when the aggressor resorts to physical violence, women reach out to the police. Nonetheless, most women do not want the aggressor to leave the home or be jailed, they simply want the police to calm the aggressor and control his violent behavior (Bui, 2003). These data are consistent with legal processes, where only one third of women asked for a restraining order, and although half of the male partners had violated the order, only one woman reported the violation (Bui, 2003).

\subsection{Personality traits that are most common in victims of IPV}

There is no personality pattern that causes someone to become a victim. The severity of the abuse was a predictor for intimacy problems (tendency to manifest difficulties, fear and evasion, and difficulties with sexual behavior), cognitive distortion, and restricted expression personality traits (Torres et al., 2013). However, abuse during childhood was not associated with personality traits (Torres et al., 2013). Women who have experienced some type of violence by their partners exhibited higher scores on schizoid, avoidant, and self-destructive personality scales, as well as on the three pathological personality scales (schizotypal, borderline, and paranoid) (Pico-Alfonso et al., 2008). There is an association between borderline personality disorder and a greater probability to be a victim of violence perpetrated by an intimate partner (Sansone et al., 2007).

By the other hand, adverse socioeconomic conditions potentiate low self-esteem and insecurity among men, which makes them resort to violence as compensatory behavior (Pandey et al., 2009). Men who grew up in a violent parental environment and/or experienced abuse as children are more likely to perpetuate abuse toward their partners (Rosenbaum \& O'Leary, 1981; Verma \& Collumbien, 2003). These men exhibit a deficit of positive behavior and an abundance of negative behaviors/attitudes (Walker \& Browne, 1985). During the relationship, aggressors exhibited sexual problems, $27 \%$ reported problems related to semen, $13 \%$ experienced problems with erections or ejaculation, and $32 \%$ had problems with sexual performance (Verma \& Collumbien, 2003).

The manner in which gender roles are defined means that women do not develop the appropriate self-protection skills (Walker \& Browne, 1985). For example, a study conducted in Spain showed that older women with more children need to overcome more obstacles in order to leave their partners, who typically provide for them financially (RuizPerez et al., 2006). In addition, these women, who are commonly unemployed, have lower levels of education and qualification, which may hinder their ability to be successfully independent (Ruiz-Perez et al., 2006), but it is not possible to know which personality traits these women exhibit.

Aggravating an already complex framework, the victim protection system is considered ineffective due to the lack of appropriate reintegration and financial aid, in order for women to have the support necessary to leave the abusive relationship (Georgiades, 2003; Kelmendi, 2015). Only 7\% of abused women seek help from organizations for battered women (Ruiz-Perez et al., 2006). Individuals who directly interact with victims often place blame on them and minimize the violence they have experienced (Kelmendi, 2015; Yoshihama, 2002). On the other hand, the frequency of aggressions (70\% were daily) points toward the acceptance of violence as common behavior in the couple's relationship, which partly explains the delay by victims to seek help, with $86.7 \%$ of them having no social support during the traumatic situation (Alonso \& Labrador, 2008). Women who exhibit self-blame (Andrews \& Brewin, 1990; Georgiades, 2003) feel the same need for social support, but unlike the women who do not blame themselves, they fail to achieve it with the same ease (Andrews \& Brewin, 1990). In cases of physical violence, in $92 \%$ of abused women, only 50\% received medical care (Alonso \& Labrador, 2008). In fact, it is common for victims of IPV to receive poor support from their social network and to experience negative reactions in response to the violence they suffered (Andrews \& Brewin, 1990). Once more, personality traits of these women are not expressed.

Due to the traumatic effects of violence, victims have a greater difficulty to reflect on themselves and their relationship, with the concern for their children being the main motivation to seek help (Lima \& Werlang, 2011), since $66 \%$ of women reported that their children witnessed the episodes of abuse (Fuentes et al., 2008). Physical abuse during childhood, sexual abuse, and witnessing interparental violence may reflect a lack of concern for the child's feelings, or the inability to respond to them, eventually revealing passive traits of personality, thus providing a model for emotional abuse in adulthood (Bensley et al., 2003) (See Table 1).

\section{Discussion}

This literature review aimed to understand: (1) consequences of different types of violence for the victims of IPV, (2) the factors that contribute to remaining in the abusive relationship, and (3) the personality traits that are most common in victims of IPV.

Among the types of violence committed, psychological violence was most frequent, with victims being abused daily (46\%) or weekly (41\%) (Fuentes et al., 2008). Violence may begin during the dating period (Fuentes et al., 2008; Pérez-Testor et al., 2007) and has a tendency to escalate over the years (Pandey et al., 2009). Violence is often perpetrated toward both their partner and their children (Pérez-Testor et al., 2007; Sarasua et al., 2007).

Gender roles that attribute authority to men, lack of family support, and shame lead to the vulnerability of violence against women (Kelmendi, 2015). Of $92 \%$ of physically abused women, only $50 \%$ received medical care, which proves the lack of resources and social support or even the denial to ask for help after the abuse (Alonso \& 


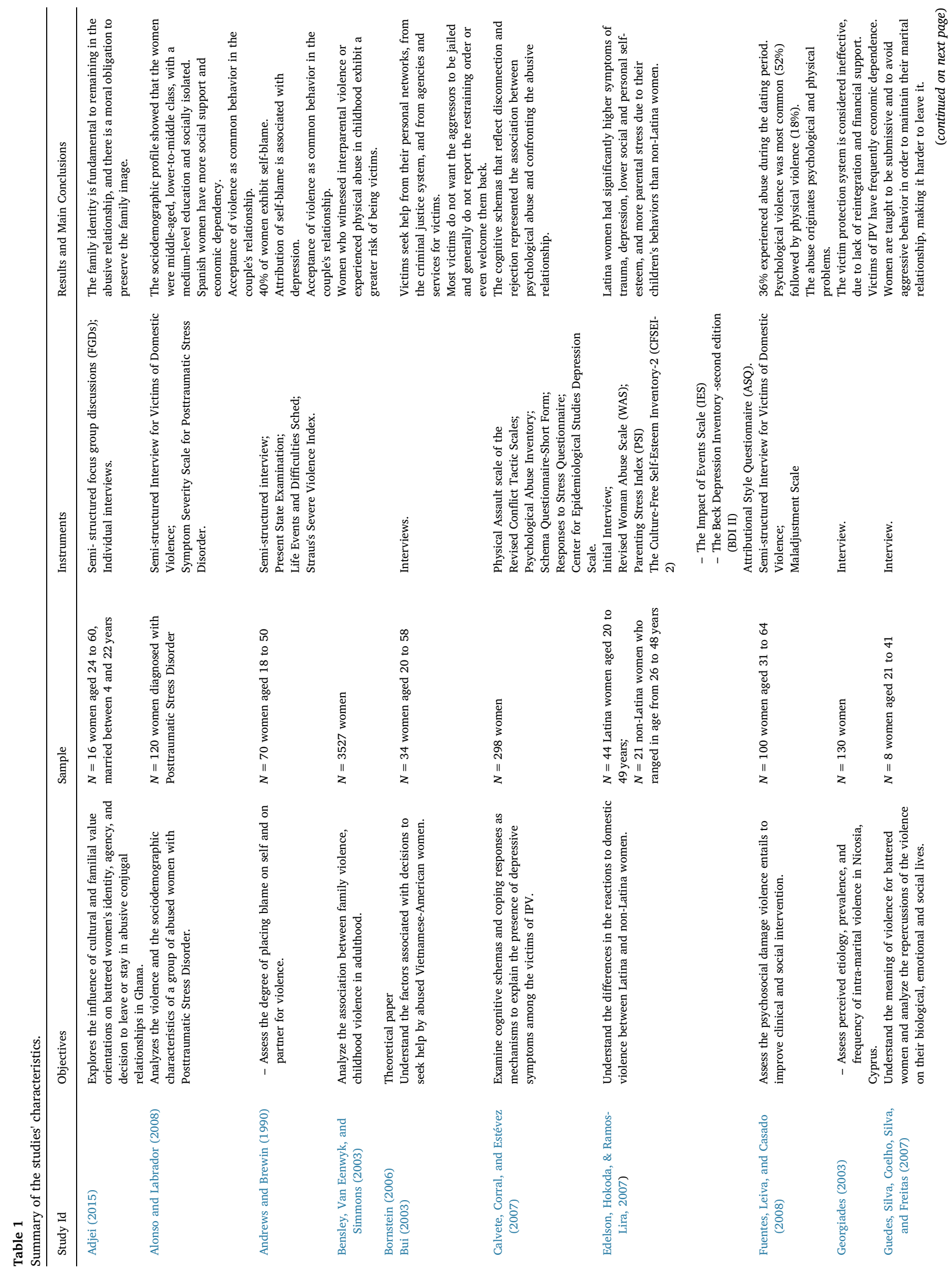




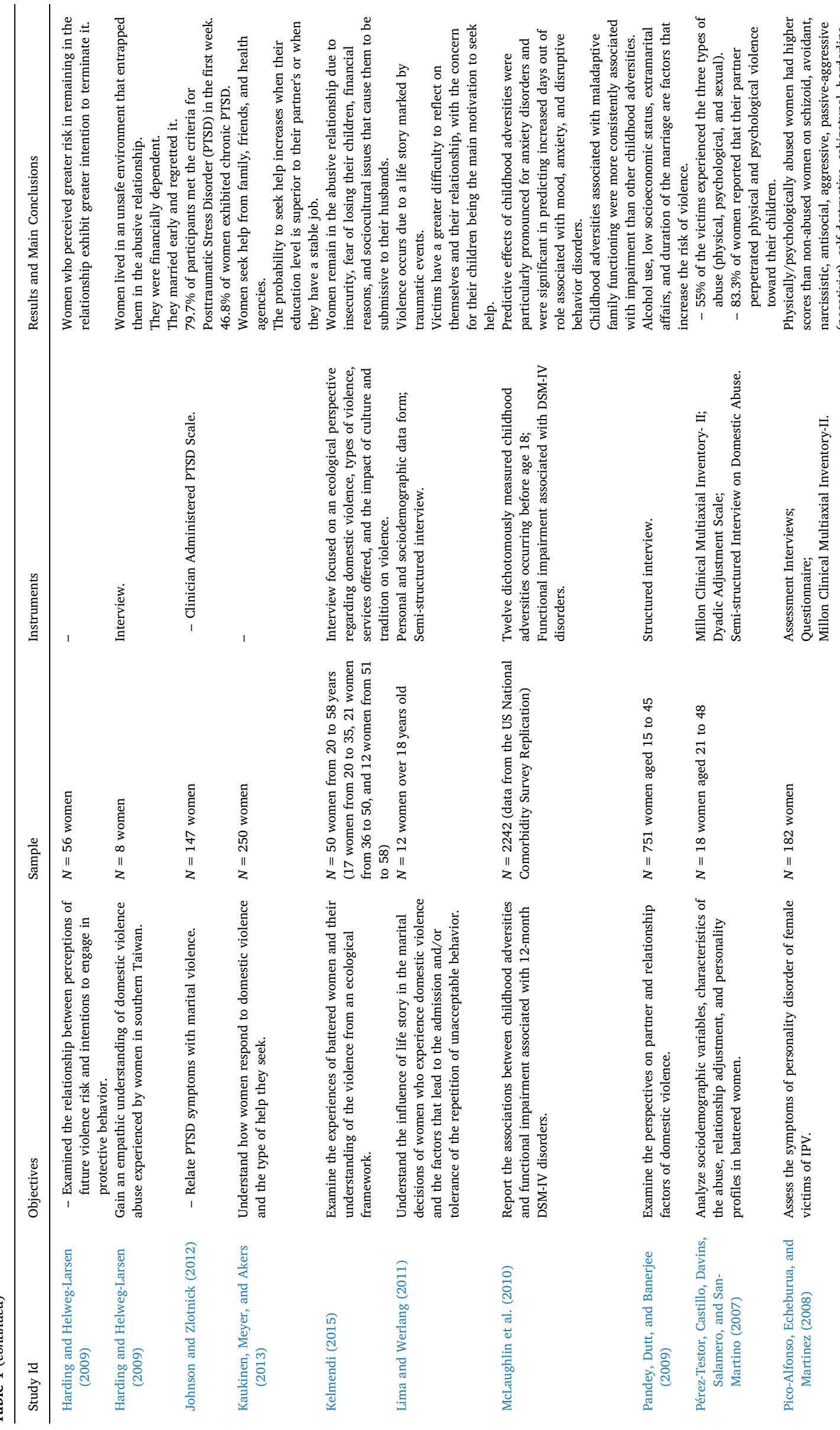




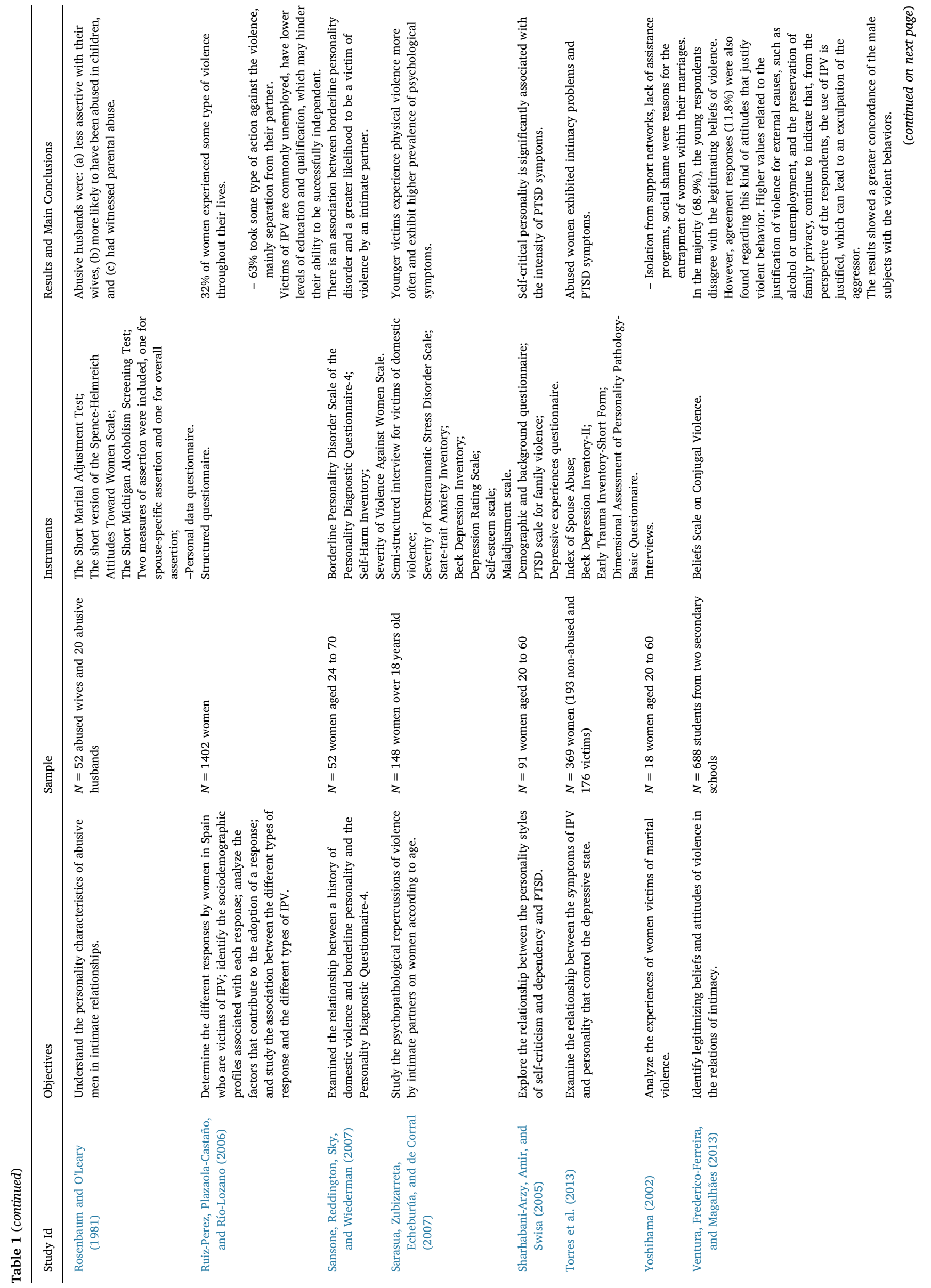


Labrador, 2008). This occurs due to the cultures that approve violence against women, as well as the lack of an effective system that would provide the necessary conditions for the reintegration of women (Kelmendi, 2015).

There are visible cultural differences regarding social support, with only $37 \%$ of immigrants and Mexicans reporting any type of support. This low percentage may be explained by the difficulty to establish new relationships in the country of residence, largely due to cultural differences (Alonso \& Labrador, 2008). Overall, victims do not resort to support services with the expected frequency, which may be explained by lack of knowledge about what these services provide or because they lack confidence in them (Ruiz-Perez et al., 2006).

The demands of marriage, motherhood, and the construction of the female gender identity itself as being responsible for maintaining the family structure for the children, to the women's own detriment, justifies remaining in the abusive relationship (Guedes et al., 2007). Nevertheless, there are other responsible factors such as economic dependency (Guedes et al., 2007; Kaukinen et al., 2013), insecurity, lack of family support (Alonso \& Labrador, 2008; Bui, 2003; Guedes et al., 2007; Kelmendi, 2015), and fear of endangering their own lives (Hsieh et al., 2009; Pérez-Testor et al., 2007).

Women who believe their marriage is doing well, minimizing the conflicts and abuse, reveal an inability to perceive their relationship as problematic. Adaptive cognitive schemas causes the victims to continue to assess the positive aspects of the relationship and not perceive the danger as a high risk, thus reducing active attempts to change their situation (Calvete et al., 2007; Pérez-Testor et al., 2007). Conversely, maladaptive schemas comprise beliefs regarding the unavailability of others to provide support and that other people with hurt the victim. These cognitive schemas may be the reason for the perceived lack of social support among victims of IPV (Calvete et al., 2007).

It becomes important to establish a diagnosis, if it exists, particularly, of borderline personality disorder in order to facilitate the victim's process of leaving the relationship. This is because, if the disorder is present, psychological treatment is more time-consuming, due to attachment and issues related to maintaining the abusive relationship, in order to circumvent the involvement of the individual in future abusive relationships (Sansone et al., 2007).

In summary, although there is no personality pattern able to determine whether someone may become a victim, there are personality traits that make the victim susceptible to remaining in an abusive relationship. Women who have experienced some form of violence by their partners obtained higher scores in schizoid, avoidant, self-destructive, schizotypal, borderline, and paranoid personality scales (Pico-Alfonso et al., 2008). Therefore, they exhibit characteristics such as low personal self-esteem, family and social isolation, dependency (not only economic but also emotional dependency), insecurity, inferiority, submissiveness, pacification, and self-blame (Andrews \& Brewin, 1990; Bui, 2003; Calvete et al., 2007; Fuentes et al., 2008; Guedes et al., 2007; Hsieh et al., 2009; Lima \& Werlang, 2011; Pandey et al., 2009; Sarasua et al., 2007; Sharhabani-Arzy et al., 2005; Walker \& Browne, 1985; Yoshihama, 2002).

Therefore, measures need to be adopted, at the societal and community levels, to enhance formal support and assistance for victims of IPV, with particular emphasis on those who mention financial dependency on their partners as the main reason they stay in the violent relationship (Ruiz-Perez et al., 2006). A first step may be to focus on education, by expanding victims' knowledge of the existence of various support sources and their role in offering avenues for victims to leave or terminate violent relationships (Kaukinen et al., 2013).

Moreover, changes should be made at a policy level in order to advance measures to end IPV and provide support for victims, both financially and in terms of their reintegration, should they choose to leave the violent relationship. These measures may include expanding and improving victim protection systems and services (e.g., women's shelters), as well as mental health resources, educational programs, and 
employment opportunities (Kaukinen et al., 2013). This last issue is particularly relevant, as it has been shown that, if women are employed, they are more likely to seek help from family, friends and the authorities, as opposed to when they are unemployed and dependent on their partner (Kaukinen et al., 2013).

On a societal level, there needs to be a change in the discourse surrounding victims. Too often victims are blamed for the violence they suffer, not only by the general public but, more alarmingly, by the various professionals who work with these victims, such as police officers, social workers, and healthcare professionals (Kelmendi, 2015). Therefore, it is important to disseminate accurate information and promote awareness among the general public with regard to IPV, as well as improve the training and education of professionals who work with these victims, in order to promote better, evidence-based practice.

This systematic review is not without limitations. Although a thorough and comprehensive search was attempted, using rigorous criteria, there is a possibility that some relevant studies, due to their unavailability or inaccessibility, were not included in this systematic review. In addition, it is also possible that studies without significant findings were not included in this review, due to the difficulty that exists in publishing these types of results. For these reasons, publication bias is difficult to overcome.

Nonetheless, despite these limitations, this systematic review contributes to the understanding of the IPV phenomenon and provides some implications for practice. Indeed, this review offers valuable information for clinical practice and intervention with victims of IPV, by bringing to light specific personality traits, cognitive schemas or possible diagnoses that are most common among these victims and make them more vulnerable to remaining in violent relationships. Furthermore, this review also offers suggestions, at the community and societal levels, of measures and initiatives that may be adopted among professionals who work with these victims, and taken into consideration by policy-makers, in order to enhance the formal support system for victims who wish to leave a relationship marked by IPV.

\section{References}

Adjei, S. (2015). Entrapment of victims of spousal abuse in Ghana. Journal of Interpersonal Violence, 32(5), 730-754. https://doi.org/10.1177/0886260515586375.

Alonso, E., \& Labrador, F. (2008). Características sociodemográficas y de la violencia de pareja en mujeres maltratadas con trastorno de estrés postraumático: Un estudio comparativo de víctimas españolas, inmigrantes y mexicanas [Sociodemographic characteristics and violence of couples in battered women with post-traumatic stress disorder: A comparative study of Spanish, immigrant and Mexican victims]. Revista Mexicana de Psicología, 25(2), 271-282.

Amoakohene, I. (2004). Violence against women in Ghana: A look at women's perceptions and review of policy and social responses. Social Science \& Medicine, 59(11), 2373-2385. https://doi.org/10.1016/j.socscimed.2004.04.001.

Andrews, B., \& Brewin, C. (1990). Attributions of blame for marital violence: A study of antecedents and consequences. Journal of Marriage and Family, 52(3), 757-767. https://doi.org/10.2307/352940.

Antai, D., \& Antai, J. (2008). Attitudes of women toward intimate partner violence: A study of rural women in Nigeria. Rural and Remote Health, 8(3), 996.

APAV (2018). Estatísticas APAV: Relatório anual 2017. Lisboa: Associação Portuguesa de Apoio à Vítima.

Bensley, L., Van Eenwyk, J., \& Simmons, K. (2003). Childhood family violence history and women's risk for intimate partner violence and poor health. American Journal of Preventive Medicine, 25(1), 38-44. https://doi.org/10.1016/s0749-3797(03)00094-1.

Blum, H. (1982). Psychoanalytic reflections on the beaten wife syndrome. In M. Kirkpatnck (Ed.). Women's sexual experiences. Explorations of the dark continent (pp. 263-267). New York: Plenum.

Bornstein, R. (2006). The complex relationship between dependency and domestic violence: Converging psychological factors and social forces. American Psychologist, 61(6), 595-606. https://doi.org/10.1037/0003-066x.61.6.595.

Bui, H. (2003). Help-seeking behavior among abused immigrant women. Violence Against Women, 9(2), 207-239. https://doi.org/10.1177/1077801202239006.

Calvete, E., Corral, S., \& Estévez, A. (2007). Cognitive and coping mechanisms in the interplay between intimate partner violence and depression. Anxiety, Stress, \& Coping, 20(4), 369-382. https://doi.org/10.1080/10615800701628850.

Counts, D., Ayers, D., Brown, J., \& Campbell, J. (1992). Sanctions and sanctuary: Cultural perspectives on the beating of wives. Boulder, CO: Westview.

Craven, D. (1997). Sex differences in violent victimization, 1994 (special report). Washington, DC: U.S. Department of Justice, Bureau of Justice Statistics.

Edelson, M., Hokoda, A., \& Ramos-Lira, L. (2007). Differences in effects of domestic violence between Latina and non-Latina women. Journal of Family Violence, 22(1), 1-10. https://doi.org/10.1007/s10896-006-9051-1.

Federal Bureau of Investigation (1995). Uniform crime reports for the United States, 1994. Washington, DC: U.S. Department of Justice.

FIDA-Ghana (International Federation of Women Lawyers) (2013). The raging war of spousal violence. Retrieved from http://www.fidaghana.org/the-raging-warofspousal-violence/.

Finkelhor, D., Gelles, R., Hotaling, G., \& Straus, M. (1983). The dark side of families. Beverly Hills: CA Sage.

Fischbach, R., \& Herbert, B. (1997). Domestic violence and mental health: Correlates and conundrums within and across cultures. Social Science and Medicine, 45(8), 1161-1176. https://doi.org/10.1016/S0277-9536(97)00022-1.

Fuentes, J., Leiva, P., \& Casado, I. (2008). Violencia contra las mujeres en el ámbito doméstico: Consecuencias sobre la salud psicossocial [Violence against women in the domestic sphere: Consequences on psychosocial health]. Anales de Psicología, 24(1), $115-120$.

Garcia-Moreno, C., Jansen, H., Ellsberg, M., Heise, L., \& Watts, C. (2006). Prevalence of intimate partner violence: Findings from the WHO multi country study on women's health and domestic violence. The Lancet, 368(9543), 7-13. https://doi.org/10.1016/ S0140-6736(06)69523-8.

Georgiades, S. (2003). Domestic violence in Cyprus: The voices of nicosian women. Journal of Social Work Research and Evaluation, 4(2), 199-212.

González-Ortega, I., Echeburúa, E., \& Corral, P. (2008). Variables significativas en las relaciones violentas en parejas jóvenes: Una revisión [significant variables in violent relationships in young couples: A review]. Behavioral Psychology/Psicología Conductual, 16(2), 207-225.

Guedes, R., Silva, A., Coelho, E., Silva, C., \& Freitas, W. (2007). The marital violence under a gender view: Domination and possibility of destruction of the hegemonily idealized model of marriage. Online Brazilian Journal of Nursing, 6(3), 21. https://doi. org/10.5935/1676-4285.20071103.

Guimarães, M., \& Pedroza, R. (2015). Violência contra a mulher: Problematizando definições teóricas, filosóficas e jurídicas [violence against women: Problematizing theoretical, philosophical and legal definitions]. Psicologia \& Sociedade, 27(2), 256-266. https://doi.org/10.1590/1807-03102015v27n2p256.

Harding, H., \& Helweg-Larsen, M. (2009). Perceived risk for future intimate partner violence among women in a domestic violence shelter. Journal of Family Violence, 24(2), 75-85. https://doi.org/10.1007/s10896-008-9211-6.

Heise, L., Ellsberg, M., \& Gottemoeller, M. (1999a). Ending violence against women (population reports, series L, no. 11). Baltimore, MD: Johns Hopkins University School of Public Health, Population Information Program.

Heise, L., Ellsberg, M., \& Gottemoeller, M. (1999b). Ending violence against women. Population reports series L, Vol. 11. Baltimore: Johns Hopkins University School of Public Health, Population Information Program.

Heise, L., Pitanguy, J., \& Germain, A. (1994). Violencia contra la mujer: La carga oculta sobre la salud [violence against women: The hidden burden on health]. Washington, D.C: Organización Panamericana de la Salud.

Hernando, A. (2007). La prevención de la violencia de género en adolescentes. Una experiencia en el ámbito educativo [Prevention of gender violence in adolescents. An experience in the educational field]. Apuntes de Psicología, 25(3), 325-340.

Higgins, J., \& Green, S. (2011). Cochrane handbook for systematic reviews of interventions (Version 5.1.0). Retrieved from www.cochrane-handbook.org.

Hsieh, H., Feng, J., \& Shu, B. (2009). The experiences of taiwanese women who have experienced domestic violence. Journal of Nursing Research, 17(3), 153-160. https:// doi.org/10.1097/jnr.0b013e3181b254b8.

Jewkes, R., Levin, J., \& Penn-Kekana, L. (2002). Risk factors for domestic violence: Findings from a south African cross-sectional study. Social Science \& Medicine, 55(9), 1603-1617. https://doi.org/10.1016/s0277-9536(01)00294-5.

Johnson, D., \& Zlotnick, C. (2012). Remission of PTSD after victims of intimate partner violence leave a shelter. Journal of Traumatic Stress, 25(2), 203-206. https://doi.org/ 10.1002/jts.21673.

Johnson, H., \& Sacco, V. (1995). Researching violence against women: Statistics Canada's national survey. Canadian Journal of Criminology, 37(3), 281-304.

Kaukinen, C., Meyer, S., \& Akers, C. (2013). Status compatibility and help-seeking behaviors among female intimate partner violence victims. Journal of Interpersonal Violence, 28(3), 577-601. https://doi.org/10.1177/0886260512455516.

Keisatsucho [National Police Agency] (1995). Hanzai tokeisho: Heisei 6 nen no hanzai [criminal statistics in 1994]. Tokyo: Author.

Kelmendi, K. (2015). Domestic violence against women in Kosovo. Journal of Interpersonal Violence, 30(4), 680-702. https://doi.org/10.1177/0886260514535255.

Kumagai, F. (1979). Social class, power and husband-wife violence in Japan. Journal of Comparative Family Studies, 10(1), 91-105.

Kumagai, F., \& Straus, M. (1983). Conflict resolution tactics in Japan, India, and the USA. Journal of Comparative Family Studies, 14(3), 377-392.

Landis, J., \& Koch, G. (1997). The measurement of observer agreement for categorical data. Biometrics, 33(1), 159-174. https://doi.org/10.2307/2529310.

Levinson, D. (1989). Family violence in cross-cultural perspective. Newbury Park, CA: Sage Publications.

Lima, G., \& Werlang, B. (2011). Mulheres que sofrem violência doméstica: contribuições da psicanálise [women who suffer domestic violence: Contributions of psychoanalysis]. Psicologia em Estudo, 16(4), 511-520. https://doi.org/10.1590/s1413 73722011000400002.

McLaughlin, K., Green, J., Gruber, M., Sampson, N., Zaslavsky, A., \& Kessler, R. (2010). Childhood adversities and adult psychopathology in the National Comorbidity Survey Replication (NCS-R) III: Associations with functional impairment related to DSM-IV disorders. Psychological Medicine, 40(5), 847-859. https://doi.org/10.1017/ s0033291709991115. 
Mendes, J., Duarte, M., Araújo, P., \& Lopes, R. (2013). Violência e relações de intimidade no ensino superior em Portugal: Representações e práticas. Teoria e Sociedade, 21(1), 87-110. Retrieved from https://www.ces.uc.pt/myces/UserFiles/livros/1097_Artigo_ Teoria\%20 $\% 20$ Sociedade_30.01.pdf.

Natera, G., Tiburcio, M., Berenzon, S., \& López, E. (1997). Marital violence in Mexico and its relationship to excessive drinking. Contemporary Drug Problems, 24(4), 787-804. https://doi.org/10.1177/009145099702400407.

Ofei-Aboagye, O. (1994). Altering the strands of the fabric: A preliminary look at domestic violence in Ghana. Feminism and the Law, 19(4), 924-938. https://doi.org/10. $1086 / 494945$.

Pandey, G., Dutt, D., \& Banerjee, B. (2009). Partner and relationship factors in domestic violence. Journal of Interpersonal Violence, 24(7), 1175-1191. https://doi.org/10. $1177 / 0886260508322186$.

Pérez-Testor, C., Castillo, J., Davins, M., Salamero, M., \& San-Martino, M. (2007). Personality profiles in a group of battered women: Clinical and care implications. Journal of Family Violence, 22(2), 73-80. https://doi.org/10.1007/s10896-0069057-8.

Pico-Alfonso, M., Echeburua, E., \& Martinez, M. (2008). Personality disorder symptoms in women as a result of chronic intimate male partner violence. Journal of Family Violence, 23(7), 577-588. https://doi.org/10.1007/s10896-008-9180-9.

Ramírez-Rodríguez, J., \& Uribe-Vázquez, G. (1993). Mujer y violencia: Un hecho cotidiano [woman and violence: An everyday fact]. Salud Pública de México, 35, 148-160.

Ravazzola, M. (1997). Violencia familiar: El abuso relacional Como un ataque a los derechos humanos [family violence: Relational abuse as an attack on human rights]. Sistemas Familiares, 23, 29-42.

Redondo, J., Pimentel, I., \& Correia, A. (2012). Manual sarar - sinalizar, apoiar, registar avaliar, referenciar: Uma proposta de manual para profissionais de saúde na área da violência familiar/entre parceiros íntimos [Manual to heal - to signal, to support, to register, to evaluate, to refer: A proposal for a manual for health professionals in the area of family violence/between intimate partners]. Centro Hospitalar Universitário de Coimbra.

Rosenbaum, A., \& O'Leary, K. (1981). Marital violence: Characteristics of abusive couples. Journal of Consulting and Clinical Psychology, 49(1), 63-71. https://doi.org/10.1037// 0022-006x.49.1.63.

Ruiz-Perez, I., Plazaola-Castaño, J., \& Río-Lozano, M. (2006). How do women in Spain deal with an abusive relationship. Journal of Epidemiology \& Community Health, 60(8), 706-711. https://doi.org/10.1136/jech.2005.041624.

Saltijeral, M., Ramos, L., \& Caballero, M. (1999). Características Psicosociales de Mujeres Maltratadas: Efectos en su salud mental [Psychosocial characteristics of battered women: effects in their mental health]. Reporte Interno no publicado [Intern Report Unpublished]Instituto Nacional de Psiquiatría.

Sansone, R., Reddington, A., Sky, K., \& Wiederman, M. (2007). Borderline personality symptomatology and history of domestic violence among women in an internal medicine setting. Violence and Victims, 22(1), 120-126. https://doi.org/10.1891/ 088667007780482883.

Sarasua, B., Zubizarreta, I., Echeburúa, E., \& de Corral, P. (2007). Perfil psicopatológico diferencial de las víctimas de violencia de pareja en función de la edad [Differential psychopathological profile of victims of intimate partner violence according to age]. Psicothema, 19(3), 459-466.

Semaan, I. (2004). Battered women's agency: Beyond staying and leaving. Paper presented at the annual meeting of the American Sociological Association, Hilton San Francisco, CA. Retrieved from http://www.allacademic.com/meta/p110515 index.html.

Shainess, N. (1979). Vulnerability to violence masochism as a process. American Journal of Psychotherapy, 33(2), 174-189. https://doi.org/10.1176/appi.psychotherapy.1979. 33.2.174.

Sharhabani-Arzy, R., Amir, M., \& Swisa, A. (2005). Self-criticism, dependency and posttraumatic stress disorder among a female group of help-seeking victims of domestic violence in Israel. Personality and Individual Differences, 38(5), 1231-1240. https:// doi.org/10.1016/j.paid.2004.08.006.

Shiroma, M. (1996). Salud reproductiva y violencia contra la mujer: Un análisis desde la perspectiva de género [Reproductive health and violence against women: An analysis from a gender perspective]. Asociación Mexicana de Población/Consejo Estatal de Población de Nuevo León, El Colegio de México.

Shrader Cox, E., \& Valdéz Santiago, R. (1992). La violencia hacia la mujer Mexicana como problema de salud pública: La incidencia de la violencia doméstica en una microregión de Ciudad Nezahualcóyotl [Violence against Mexican woman as a public health problem: The incidence of domestic violence in an area from Ciudad Nezahualcóyotl]. México: Centro de Investigación y Lucha Contra la Violencia Doméstica (CECOVID).

Torres, A., Garcia-Esteve, L., Navarro, P., Tarragona, M., Imaz, M., Ascaso, C., ... MartínSantos, R. (2013). Relationship between intimate partner violence, depressive symptomatology, and personality traits. Journal of Family Violence, 28(4), 369-379. https://doi.org/10.1007/s10896-013-9502-4.

United Nations General Assembly (1993). Declaration on the elimination of violence against women. A/RES/487104. 1994.

Ventura, M., Frederico-Ferreira, M., \& Magalhães, M. (2013). Violência nas relações de intimidade: Crenças e atitudes de estudantes do ensino secundário [violence in intimacy relations: Beliefs and attitudes of secondary school students]. Revista de Enfermagem Referência, 3(11), 95-103. https://doi.org/10.12707/riii12120.

Verma, R., \& Collumbien, M. (2003). Wife beating and the link with poor sexual health and risk behavior among men in urban slums in India. Journal of Comparative Family Studies, 34(1), 61-74.

Walker, L., \& Browne, A. (1985). Gender and victimization by intimates. Journal of Personality, 53(2), 179-195. https://doi.org/10.1111/j.1467-6494.1985.tb00363.x.

World Health Organization (2013). Global and regional estimates of violence against women Prevalence and health effects of intimate partner violence and non-partner sexual violence. Geneva, Switzerland: WHO Author.

Yllo, K., \& Straus, M. (1990). Patriarchy and violence against wives: The impact of structural and normative factors. In M. A. Straus, \& R. J. Gelles (Eds.). Physical violence in American families: Risk factors and adaptations to violence in 8, 145 families (pp. 383-399). New Brunswick, NJ: Transaction.

Yoshihama, M. (2002). Breaking the web of abuse and silence: Voices of battered women in Japan. Social Work, 47(4), 389-400. https://doi.org/10.1093/sw/47.4.389. 